\title{
DEFININDO ARTE
}

\author{
George Dickie
}

American Philosophical Quarterly, vol. 6, no. 3 (jul. 1969), pp. 253-256

Jean Rodrigues Siqueira

Em anos recentes foi argumentado que a expressão "obra de arte" não pode ser definida e Morris Weitz chegou até mesmo a argumentar que ser um artefato não é condição necessária para algo ser uma obra e $\operatorname{arte}^{38}$. Mais recentemente, contudo, Joseph Margolis ofereceu uma definição ${ }^{39}$ e Maurice Mandelbaum fez algumas sugestões a respeito de como definir de "arte".

Não repetirei o bem conhecido argumento de Weitz, cujas ideias tomo como representativas daqueles que sustentam que "arte" não pode ser definida, mas enunciarei sua conclusão principal e comentarei um de seus argumentos. Tampouco repetirei os argumentos de Margolis ou Mandeulbaum, mas quero destacar (1) que eles concordam que a artefatualidade é uma condição necessária da arte, e (2) que Mandelbaum aponta a importância das características não exibidas da arte para uma definição de "arte"

A principal conclusão de Weitz é que não há condições necessárias e suficientes para a definição de "arte" ou para qualquer dos subconceitos de arte, como "romance", "tragédia", "pintura", e outros. Todas essas noções são conceitos abertos e suas instanciações têm "semelhanças de família".

Weitz rejeita a artefatualidade como uma condição necessária da arte porque às vezes fazemos afirmações como "Esta madeira flutuante é uma adorável pedaço de escultura" ${ }^{41}$. Às vezes realmente falamos dessa maneira dos objetos naturais, mas nada se segue desse fato. Weitz

\footnotetext{
.* Doutorando em Educação, Arte e História da Cultura pela Universidade Presbiteriana Mackenzie e Mestre em Filosofia pela Pontifícia Universidade Católica de São Paulo (PUC/SP). Atua como professor do Curso de Filosofia do Centro Universitário Assunção (UNIFAI - SP).

${ }^{38}$ Morris Weitz, "The role of theory in aesthetics", The journal of aesthetics and art criticism, vol. 15 (1956), pp. 2735; reimpresso em Philosophy look at arts, ed. por Joseph Margolis (Nova Iorque, 1956); Paul Ziff, "The task of defining a work of art", reimpresso em Aesthetics and the philosophy of criticism, ed. por Marvin Levich (Nova Iorque, 1963); William Kennick, “Does traditional aesthetics rests on a mistake”, Mind, vol. 66, pp. 317-334.

${ }^{39}$ The language of art and art criticism (Detroit, 1965), pp. 37-47. A definição de Margolis, contudo, não é satisfatória; ver a revisão de Andrew Harrison em Philosophical Books, vol. 7 (1966), p. 19.

40"Family resemblances and generalization concerning the arts", American Philosophical Quarterly, vol. 2 (1965), pp. 219-228.

${ }^{41}$ Op. cit, p. 57.
} 
se confunde porque toma a afirmação sobre a madeira flutuante como sendo uma afirmação descritiva e ela não é. O próprio Weitz, bastante corretamente, distingue entre um uso avaliativo e um uso descritivo de "obra de arte" ${ }^{42}$, e uma vez compreendida essa distinção podemos ver que a observação sobre a madeira flutuante é uma avaliação da madeira flutuante. Mas é, certamente, o sentido descritivo de "obra de arte" que está em pauta quando se levanta a questão de se "arte" pode ser definida. Eu defendo que o uso descritivo de "obra de arte" é utilizado para indicar que uma coisa pertence a certa categoria de artefatos. A propósito, o sentido avaliativo pode ser aplicado a artefatos e também a não artefatos, como quando dizemos "Aquela pintura é uma obra de arte". Tais observações não têm a intenção de ser tautologias.

Antes de prosseguir com a discussão a respeito da segunda condição da definição do sentido descritivo de "arte", será útil distinguir o conceito genérico de arte dos vários subconceitos que caem sob ele. Bem pode ser o caso de que todos ou alguns dos subconceitos de arte, como romance, tragédia, cerâmica, escultura, pintura, e outros, careçam de condições necessárias e suficientes e ainda assim seja o caso de que "obra de arte", que é o gênero de todos esses subconceitos, possa ser definido. Por exemplo, talvez não haja nenhuma característica que todas as tragédias tenham que pudesse diferenciá-las das comédias, peças satíricas, happenings e outras semelhantes dentro do domínio da arte. À luz do que foi dito, mesmo se esse fosse o caso, as tragédias e todas as outras obras de arte teriam pelo menos uma característica em comum, a saber, a artefatualdiade. Talvez artefatualidade e alguma ou mais características das obras de arte as distingam da não arte. Se todos ou alguns dos subconceitos de arte não podem ser definidos e, como penso ser o caso, “arte” pode, então em parte Weitz está correto.

Assumindo que a artefatualidade é o gênero da arte, ainda fica faltando a diferença. Essa segunda condição será uma propriedade social da arte. Além do mais, essa propriedade social será, na terminologia de Mandelbaum, uma propriedade não exibida, relacional.

W. E. Kennick afirma que tal abordagem a respeito da definição de "arte" é fútil. Ele argumenta, a partir de fatos como o de que os antigos egípcios selavam pinturas e esculturas nas tumbas, para a conclusão de que "A tentativa de definir Arte em termos do que fazemos com certos

${ }^{42}$ Ibid. p. 56. 
objetos está tão condenada quanto qualquer outra" ${ }^{\text {43. }}$. Há diversas dificuldades no argumento de Kennick. Primeiramente, do fato de que os egípcios selavam pinturas e esculturas em tumbas não se segue que eles as considerassem diferentemente do modo como geralmente o fazemos. Eles poderiam, na verdade, tê-las colocado ali para os mortos apreciarem, ou simplesmente porque elas pertenciam à pessoa morta, ou por alguma outra razão. A prática egípcia não prova uma diferença radical entre nossa concepção de arte e a deles de modo a uma definição que subsumisse ambas ser impossível. Em segundo lugar, não é preciso assumir uma concepção de arte em comum entre nós e os antigos egípcios (ou qualquer outro grupo). Eu ficaria feliz em ser capaz de especificar as condições necessárias e suficientes para o conceito de arte que nós temos (nós, americanos contemporâneos, nós, ocidentais contemporâneos, nós, ocidentais desde a organização do sistema das artes no ou por volta do século XVIII - não estou certo a respeito dos exatos limites do "nós"). A despeito de Kennick, é mais provável que descubramos a diferença da arte ao considerarmos "o que fazemos com certos objetos", isto é, as "obras de arte". Mas, é claro, não há garantia de que qualquer coisa que nós ou um antigo egípcio possivelmente pudesse fazer com uma obra de arte lançará luz sobre o conceito de arte. Nem todo fazer revelará o que está sendo requerido.

O estimulante artigo de Arthur Danto, "O mundo da arte"44, será de ajuda aqui. Ao falar da Caixa Brillo e da Cama de Rauschenberg, ele escreve "Ver algo como arte requer algo que o olho não pode descobrir - uma atmosfera de teoria artística, um conhecimento de história da arte: um mundo da arte" ${ }^{\not 5}$. O que o olho não pode descobrir é uma complicada característica não exibida dos artefatos em questão. A "atmosfera" de que fala Danto é evasiva, mas tem um conteúdo substancial. Talvez esse conteúdo possa ser capturado em uma definição. Primeiramente, formularei a definição e então prosseguirei em sua defesa. Uma obra de arte em sentido descritivo é (1) um artefato (2) ao qual alguma sociedade ou algum subgrupo de uma sociedade atribuiu o estatuto de candidato à apreciação.

A definição fala da atribuição do estatuto de candidato à apreciação: nada é dito a respeito da apreciação efetiva e isso deixa aberta a possibilidade de obras de arte que, seja lá por qual razão, não são apreciadas. Além disso, nem todo aspecto de uma obra está incluído na candidatura à apreciação; a cor da parte de trás de uma pintura, por exemplo habitualmente não é um objeto de

\footnotetext{
${ }^{43}$ Kennick, op. cit., p. 330.

${ }^{44}$ The journal of philosophy, vol. 61 (1964), pp. 571-584.

${ }^{45}$ Ibid., p. 580.
} 
apreciação. O problema a respeito de que aspectos de uma obra de arte devem estar incluídos em sua candidatura à apreciação é uma questão que persegui em outro lugar ${ }^{46}$.

De que maneira é atribuído o estatuto de candidato à apreciação? Um artefato pendurado em um museu de arte, uma performance em um teatro, e coisas semelhantes, são sinais seguros de que o estatuto foi atribuído. Mas muitas obras de arte nunca chegam às paredes dos museus e algumas nunca são vistas por ninguém além do artista. O estatuto, portanto, tem de ser passível de atribuição por uma única pessoa que trate um artefato como candidato à apreciação, geralmente o próprio artista, embora nem sempre, uma vez que alguém pode criar um artefato sem nunca considerá-lo como um candidato à apreciação e tal estatuto ser atribuído por outra pessoa ou pessoas. Mas pode o estatuto ser atribuído tão facilmente? Nós associamos o estatuto com a cerimônia - a cerimônia de casamento, por exemplo. Contudo, a cerimônia não é o único meio para se casar; em algumas jurisdições o casamento por convivência é possível - um estatuto adquirido sem cerimônia. $\mathrm{O}$ que quero sugerir é que, assim como duas pessoas podem adquirir o estatuto de casados por convivência dentro de um sistema legal, um artefato pode adquirir o estatuto de candidato à apreciação dentro do sistema que Danto chamou de "o mundo da arte".

Uma série de questões surgem dessa noção de estatuto de candidato à apreciação e talvez tudo possa ser melhor esclarecido enunciando-as e tentando respondê-las. Provavelmente, a primeira questão é: que tipo de apreciação? Certamente a definição parece sugerir que há um tipo especial de apreciação “estética”. Apreciação não é crucial, mas algo deveria ser dito a seu respeito para preparar o caminho para o ponto crucial. O tipo de apreciação que tenho em mente é simplesmente o tipo característico de nossas experiências de pinturas, poesias, romances e coisas semelhantes. Essa observação parece colapsar a definição em circularidade, mas não o faz porque "obra de arte" (o termo definido) não aparece na explicação da apreciação, apenas termos subconceitos aparecem. Outro problema aparente é que as obras de arte são tão diferentes umas das outras - por exemplo, comédias são muito diferentes de tragédias - que parece improvável que a apreciação característica de nossa experiência de um tipo de arte tenha algo em comum com a apreciação característica de nossa experiência de outro tipo de obra. Mas pinturas, poemas, e peças são os objetos de nossa apreciação e o fato de que os objetos diferem consideravelmente não significa que as várias apreciações diferem. Na verdade, se por “apreciação" queremos dizer algo

\footnotetext{
${ }^{46} \mathrm{Em}$ meu "Art narrowly and broadly speaking”, American Philosophical Quarterly, vol. 5 (1968), pp. 71-77, onde analiso a noção de objeto estético. O assunto do presente ensaio é o conceito de arte que, embora ligado à noção de objeto estético, é distinto dela.
} 
como "ao experenciar as qualidade de uma coisa as consideramos meritória ou de grande valor", então não há problema em relação à semelhança das várias apreciações.

Agora pode ser visto que a apreciação não servirá para tirar a subclasse das obras de arte da classe dos artefatos - ela é muito ampla: muitos artefatos que obviamente não são obras de arte são apreciados. Para tirar a classe das obras de arte é preciso destacar mais a atribuição do estatuto de candidato do que a apreciação. Quando, por exemplo, um vendedor de suprimentos de encanamento espalha seus produtos diante de nós, ele os apresenta imediatamente para nossa apreciação, mas a apresentação não é uma atribuição do estatuto de candidato, é simplesmente um dispor diante de nós. Mas qual é a diferença entre "dispor diante" e "atribuir o estatuto de candidato"? A diferença é análoga à diferença entre meu proferir "Eu declaro este homem candidato ao conselho municipal" e o líder da comissão de eleição proferindo a mesma sentença e agindo em sua capacidade oficial. Quando profiro a sentença ela não surte efeito porque eu não fui empossado com qualquer autoridade nesse sentido. É claro que essa analogia não é completa linhas de autoridade no mundo político-legal são, em grande medida, explicitamente definidas e incorporadas à lei, ao passo que as linhas de autoridade (ou algo semelhante à autoridade) no mundo da arte não estão codificadas em lugar nenhum. $\mathrm{O}$ mundo da arte conduz seus negócios no nível da prática costumeira. Ainda assim, há uma prática e isso define uma instituição social. Retornando ao exemplo do encanamento, a apresentação do vendedor é diferente do ato de Duchamp, superficialmente similar, de dispor um urinol por ele batizado de "Fonte" naquela apresentação de arte agora famosa. O ponto é que o ato de Duchamp aconteceu dentro de um certo contexto institucional, e isso faz toda diferença. Nosso vendedor de suprimentos de encanamento poderia fazer o que Duchamp fez, isto é, converter um urinol em obra de arte, mas ele provavelmente não o faria - tais idéias inusitadas parecem ocorrer apenas aos artistas com bizarro senso de humor. Lembrem-se, por favor, que quando eu digo que a "Fonte" é uma obra de arte, não estou dizendo que ela seja uma boa obra. E, ao fazer essa observação, tampouco estou insinuando que ela seja ruim também.

Os "ready-mades" de Duchamp levantam a questão - "Se urinóis, pás de neve, cabides de chapéus, podem se tornar obras de arte, porque objetos naturais, como uma madeira flutuante, não podem? E, é claro, madeiras flutuantes e outros objetos naturais podem se tornar obras de arte se qualquer entre um número de coisas for feita com eles. Uma coisa que faria bem isso seria recolher uma, levá-la para casa e pendurá-la em uma parede. Outra coisa que serviria seria recolher uma e inscrevê-la em uma exibição. (A propósito, eu estava assumindo que a sentença de Weitz com 
relação à madeira flutuante referia-se à sua situação comum em uma praia e intocada pela mão humana). Isso significa que objetos naturais que se tornam obras de arte adquirem sua artefatualidade (são artefatualizados) ao mesmo tempo em que o estatuto de candidato à apreciação lhe é atribuído. Mas talvez uma coisa similar ordinariamente aconteça com as pinturas, poemas, etc.; eles passam a existir como artefatos ao mesmo tempo em que o estatuto de candidatos à apreciação é atribuído a eles. (Ser um artefato e ser um candidato à apreciação, é claro, não é a mesma coisa - são duas propriedades de uma única coisa que podem ser adquiridas ao mesmo tempo). Um caso um pouco mais complicado seria o artefato de uma cultura primitiva que desempenhou uma função em um sistema religioso e que não possuía nenhuma função artística no sentido aqui desenvolvido. Tal artefato poderia se tornar uma obra de arte em nossa cultura de maneira semelhante àquela em que a madeira flutuante poderia se tornar uma obra de arte. Todavia, esse objeto religioso que se tornasse uma obra de arte seria um artefato em dois sentidos, mas a madeira flutuante em apenas um. (Não estou sugerindo que algo não possa ser um objeto religioso e uma obra de arte ao mesmo tempo - há muitos contra-exemplos disso em nossa cultura).

Uma questão que frequentemente surge em conexão com discussões sobre o conceito de arte é "Como devemos conceber as pinturas feitas por indivíduos como Betsy, o chimpanzé do Zoológico de Baltimore?" Tudo depende do que é feito com as pinturas. (Note que, sem hesitar, eu chamei os objetos pinturas, embora não tenha certeza a respeito de seu estatuto enquanto obra de arte). For exemplo, O Museu Field de História Natural recentemente exibiu algumas pinturas de chimpanzés. No caso dessas pinturas devemos dizer que elas não são obras de arte. Todavia, se elas tivessem sido exibidas a poucas milhas de distância no Instituto de Arte de Chicago, elas seriam obras de arte. (Se, por assim dizer, o diretor do Instituto de Arte assim se expusesse dessa maneira publicamente). Tudo depende do contexto institucional.

Concluindo, seria conveniente considerar de que maneira a definição aqui oferecida difere de algumas definições tradicionais. (1) Ela não tenta passar clandestinamente uma concepção de boa arte para a definição de "arte". (2) Ela não é, para usar um termo de Margolis, "sobrecarregada", como a que Margolis cita como sendo um exemplo horrível: "arte é uma atividade humana que explora, e assim cria, nova realidade em uma maneira visionária e suprarracional, e a apresenta simbolica ou metafoncamente ${ }^{47}$, como um todo microcósmico

\footnotetext{
${ }^{47} \mathrm{Há}$, aparentemente, dois erros tipográficos aqui. Margolis cita a palavra como "metafonicamente" e no texto original lê-se "metafoncamente". Uma leitura do texto original indica que deveria ser "metaforicamente".
} 
significando um todo macrocósmico"48. (3) Ela não contém qualquer comprometimento com alguma teoria metafísica ou não empírica, em contraste, por exemplo, com a teoria de que a arte é irreal. (4) Ela é ampla o suficiente de modo que aquelas coisas geralmente reconhecidas como arte podem ser trazidas sob ela sem esforço indevido, em contraste, por exemplo, com a definição da imitação, que exige um enorme esforço na tentativa de mostrar que toda obra de arte é uma imitação de algo. (5) Ela leva em consideração (ou pelo menos tenta fazê-lo) as práticas efetivas do mundo da arte do passado e do presente.

Agora, o que venho dizendo pode soar como se estivesse dizendo que "uma obra de arte é um objeto a respeito do qual alguém disse 'eu batizo este objeto uma obra de arte"”. E eu acho que é algo bastante dessa maneira. Então alguém pode fazer uma obra de arte da orelha de uma porca, mas isso não significa, é claro, que ela seja uma bolsa de seda ${ }^{49}$.

\footnotetext{
${ }^{48}$ Op. cit., p. 44. A passagem citada é de "What is art?", de Erick Kahler, em Problems in aesthetics, ed. por Morris Weitz (Nova Iorque, 1959).

${ }^{49}$ Devo agradecimentos a Monroe Beardsley, Marcia Eaton, William Hayes, Arnold Levinson e Maurice Mandelbaum, que leram o manuscrito deste artigo e fizeram várias sugestões úteis.
} 